\title{
Pierre Antoine Grillet at 75: a tribute
}

\section{Jonathan Leech ${ }^{1}$}

Received: 20 December 2016 / Accepted: 6 March 2017 / Published online: 16 March 2017

(C) Springer Science+Business Media New York 2017

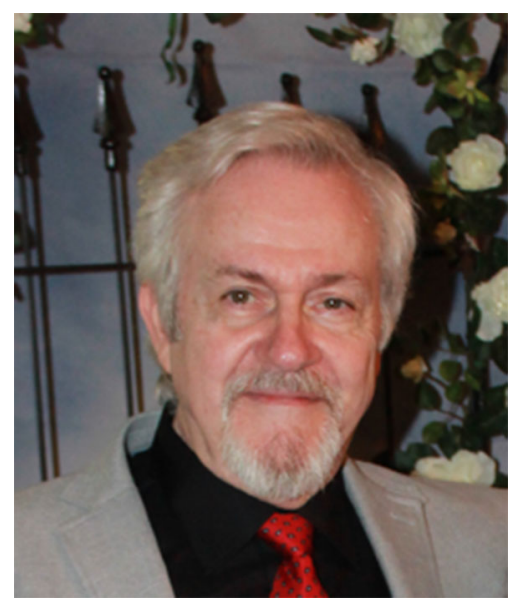

The context of our honoree's birth was the outbreak of World War II. His father, Antoine Grillet, had met his mother, Nine (pronounced Neen), on a train in Belgium prior to the war. It was love at first sight. When the war broke out they attempted to flee the advancing German army by traveling to the Pyrenees, planning to cross the border into Spain. But while there, Nine discovered she was pregnant. Hoping to raise the child in a French environment, when the situation stabilized they returned to an

Communicated by László Márki.

$\otimes$ Jonathan Leech

leech@westmont.edu

1 Department of Mathematics, Westmont College, Santa Barbara, CA 93108, USA 
occupied Paris where their magnum opus, Pierre Antoine Grillet, was born on May 1, 1941.

Young Pierre's education began after the war in the public schools of Paris where he received a fine classical education. Following competitive examinations he was admitted to both the Ecole Polytechnique (the premier Engineering school in France) and the Ecole Normale Superieure (the premier school for mathematics and science in France), and chose the latter. At the E.N.S., although the best physics student in his class, he disappointed his instructors by choosing mathematics over physics.

Following the E.N.S., Grillet entered the Université Paris IV-Sorbonne. His interests narrowed down to semigroups and related areas, thanks in no small part to Paul Dubreil's lectures (and much to the puzzlement of Henri Cartan, his most outstanding professor at the E.N.S.). Pierre completed a Ph.D. in 1965. His dissertation, Homomorphismes principaux de tas et de groupoïdes (Principal homomorphisms of stacks and groupoids), was directed by Dubreil. For it, Grillet was awarded the Albert Châtelet Medal. This medal was given each year by the Châtelet family to the author of the best Ph.D. Thesis of the year in France in algebra or number theory, the main fields of interest to Châtelet. (Also of interest is the fact that Châtelet was one of M.-P. Schützenberger's two doctoral advisors.)

Meanwhile, A. D. Wallace had written to Dubreil asking him to recommend a recent student for an open position at the University of Florida. Dubreil recommended Grillet and thus Pierre taught there from 1965 to 1967. When the department head, John Maxfield, moved to Kansas State University, charged with the task of improving its graduate program in mathematics, Grillet went with him. He was in Kansas from 1967 to 1972, with the interruption of a year spent visiting Tulane at the invitation of A. H. Clifford. Grillet loved New Orleans and he loved Tulane. When an opening arose in 1972, he took it, remaining there until he retired in 2006.

While at Kansas State University in 1971, Grillet published "Regular categories," as Part 2 of Exact Categories and Categories of Sheaves (Lecture Notes in Mathematics, Vol. 236, Springer-Verlag) consisting of three related papers individually authored by Michael Barr, Pierre Grillet and Donovan van Osdol. Grillet's 100-page contribution, culminating several years of research in category theory, earned a commendation from Saunders MacLane. While a precise definition may be found online, suffice it to say, regular categories include the category of sets, the category of all algebras and homomorphisms in a variety of algebras, any abelian category and any elementary topos. Non-examples include the category of all topological spaces and the category of all categories. Regular categories provide a foundation for the study of what is termed, regular logic. (It should be mentioned that some category theorists wonder even now why Grillet stopped working in categories after such a grand entry. But again, he found semigroups to be more intriguing.)

As mentioned, Grillet moved to New Orleans and Tulane University in 1972, thus joining forces with A. H. Clifford, Karl Heinrich Hoffman, Michael Mislove and William Nico. In 1974 he published "Left coset extensions," a 64-page article, dedicated to Clifford on the occasion of his 65th birthday. It appeared in the Semigroup Forum (Vol. 7) and dealt both with extensions and with a cohomology theory for abelian group-valued functors that arise in the commutative case. While not published simultaneously, this paper was the first of a sequence of three papers on extensions 
and cohomology appearing in the 70s. The second, appearing in 1976, was Jonathan Leech's " $H$-Coextensions of Monoids" (Memoirs A.M.S., Vol. 157). Then "Extension theories for monoids" by Charles Wells (Semigroup Forum, Vol. 16) appeared in 1978. In all cases a (co-)extension of a monoid or semigroup $S$ is a surjective homomorphism $f: T \rightarrow S$ whose induced congruence is contained in $L$ (plus added conditions) for Grillet or in $H$ for Leech, $L$ and $H$ being the Green's relations. In the commutative case, left coset extensions $=H$-coextensions, and Grillet's cohomology is a commutative variant of a Leech's more general cohomology. Wells' paper, developed after visiting with Barr and others while at the E.T.H. in Zürich, showed how Leech cohomology fit into a general class of (co-)homology theories introduced by Jonathan Beck via triples and studied by Barr, Beck and others. Then in 1995, in "Commutative semigroup cohomology" (Communications in Algebra, Vol. 23), Grillet showed how his cohomology fit into Beck's scheme. These papers are the basis for much ongoing research in monoid/semigroup cohomology today. More later.

The 1970s, the decade of the three earlier papers above, was a period when many were studying regular semigroups. Within this milieu, Grillet was not idle. Four research announcements appeared in the Semigroup Forum in 1974 that led to "On regular semigroups and their multiplication," published in the Transactions of the A.M.S. in 1978. There, he described how multiplication works in the regular case; that is, he described how multiplication is determined by a pair of partially ordered sets, a set of groups and data relating them, all in a manner reminiscent of the ReesSushkevich picture of completely 0-simple semigroups. (Given a regular semigroup $S$, the partially ordered sets are essentially $S / R$ and $S / L$ with the groups being the maximal subgroups of $S$, one for each $D$-class.) Fortunately this information and more on regular semigroups and their structure is readily accessible in Chapter VI and those following in Grillet's informative Semigroups: an Introduction to the Structure Theory, published in 1995. Material from the Transactions paper occurs in its Section VI.6. A comprehensive and very positive review of this book may be found at: Zbl 0874.20039.

Besides information about regular semigroups in this text, there is much in Chapter IV about a major interest of Grillet: commutative semigroups. This was apparent, again in the 1970s, with the publication of several papers extending earlier work by Lászó Rédei and others on finitely generated commutative semigroups. Recall Rédei's famous result: finitely generated commutative semigroups are finitely presented. Grillet followed up by studying finitely subdirect decompositions (with only finitely many factors allowed) of finitely generated commutative semigroups, and characterizing the finitely subdirectly irreducible cases (the FSIs). See "On subdirectly irreducible commutative semigroups," Pacific J. Math. Vol. 69 (1977). To begin every finitely generated commutative semigroup is a subdirect product of finitely many FSI factors, each of course also being finitely generated and commutative. Grillet showed that any such FSI semigroup is either cancellative or a nil semigroup or a special type of combination of both. In each case he gave precise conditions for the finitely generated commutative semigroup to be FSI. E.g., in the cancellative case, the semigroup is FSI iff it is isomorphic to the additive integers or to a cyclic group of prime power order or to a numerical semigroup (a nontrivial subsemigroup of the natural numbers under addition). Some of this material was anticipated in an earlier paper, "Primary 
semigroups," Michigan Math. Journal, Vol. 22 (1975). Grillet also proved a completion theorem for finitely generated commutative semigroups in a paper by that title in Journal of Algebra, Vol. 34 (1975). In detail, a commutative semigroup $S$ is complete if (i) some power of every element in $S$ lies in a subgroup of $S$ and (ii), its semilattice of idempotents is complete as a (down) semilattice. Grillet's theorem asserts that every finitely generated commutative semigroup can be embedded in a complete finitely generated commutative semigroup having exactly as many Archimedean components. Further information may be found in Chapter IV, Sections 9 and 10, of Grillet's Semigroups. Pierre published numerous papers on commutative semigroups, with many since the 1990s appearing in Hungarian journals, a good portion being in Acta Scientiarum Mathematicarum. In particular he published several papers on their congruences. E.g., see "Congruences on free commutative semigroups," Acta Sci. Math. Vol. 67 (2001). His work has advanced significantly our understanding of commutative semigroups. His definitive monograph, Commutative Semigroups, was published by Kluwer (now absorbed into Springer) in 2001 in their series, Advances in Mathematics. The $M R$ reviewer said that it was a book "... that all students [and] researchers of this theory must have in their library."

A perusal of Grillet's extensive mathematical oeuvre will reveal a lack of publication in the 1980s. This was due to the formidable task of raising two daughters as a single parent, doing so with energy and sustained focus. Since then, however, he has published over 50 more articles plus four books, including the two mentioned above. One of his 1991 "reentry" papers was the research announcement, "Commutative semigroup cohomology" in the Semigroup Forum that preceded the above-mentioned paper by that title. A number of his later papers have been on the cohomology of commutative semigroups, with several concerned with calculating the second cohomology group that classifies extensions. See, e.g., "The commutative cohomology of finite semigroups" in J. Pure and Applied Algebra, Vol. 102 (1995). See also "Commutative nilsemigroups with zero cohomology" in Semigroup Forum, Vol. 62 (2001) and "Partially free commutative semigroups" in Acta Sci. Math. Vol. 61 (1995). The last three chapters in Grillet's Commutative Semigroups are on cohomology. Research on the cohomology theories of Grillet and Leech, commutative or not, continues. At the University of Granada, a center for research in commutative and especially numerical semigroups, research into both types of cohomology has also occurred. A current instance is "On the third cohomology group of commutative monoids" by M. CalvoCervera, A. Cegarra and B. A. Heredia, appearing in the Semigroup Forum, Vol. 92 (2016). Its classification of strictly symmetric monoidal abelian groupoids, using in part Grillet's third cohomology group, extends a classification of strictly commutative Picard categories given by Pierre Deligne and, independently, several others. Thus, although his parents never crossed into Spain during the war, work extending the research of Grillet is taking place within an easy stroll to the Alhambra.

Of course, many of Grillet's publications in his "second career" were not about cohomology, and some not even about commutative semigroups. Other repeating topics include aspects of congruence theory, computational procedures and their outcomes, and semigroup actions. Besides the three book-length publications already mentioned, Grillet has also served the wider mathematical community with two introductions to abstract algebra: first Algebra appearing in 1999 with Wiley Interscience and then a 
revised edition retitled Abstract Algebra appearing in 2007 with Springer-Verlag. The $M R$ review of Algebra stated that it “... will no doubt find its place among the top of the already good selection of introductory texts in algebra."

As his career was launched with a medal, so it was capped off by one. In appreciation for his contributions to both regular and commutative semigroups, the Bolyai Institute of the University of Szeged in Hungary awarded its Béla Szókefalvi-Nagy Medal for the year 2010 to Grillet. The citation read in part: Pierre Antoine Grillet has made significant contributions to semigroup theory. His results have provided the structure of regular semigroups, and have considerably expanded the theory of commutative semigroups. One need say no more.

However, as with all of us, other things are in Pierre's life besides mathematics. He is very proud of his two daughters, one a lieutenant in the U.S. Navy and the other a $\mathrm{Ph}$.D. in chemical engineering. He also has a keen interest in music; in particular he is an accomplished harpsichord player, having owned an instrument that, as I recall, he constructed from a kit. On a personal level, I have fond memories of summer visits to New Orleans and Tulane University in the 1970s, where I interacted with Pierre and, of course, Alfred Clifford. Our discussions were stimulating, and the hospitality extended by both gentlemen and their wives was most gracious. I also recall an evening when Pierre and I toured the club scene in the French Quarter of New Orleans. Later on, we caught up at various conferences. And I remain grateful for advice he once gave on where to submit (successfully) a paper. (The recommended journal was, yes, Hungarian.)

To conclude: Pierre Antoine Grillet, on the occasion of your 75th birthday, it is an honor to acknowledge your significant contributions to algebraic semigroups in your many papers and by your two insightful expositions on the subject, and also to acknowledge your gifts to the wider mathematical community via your expositions of modern algebra as well as your early work in category theory. Your body of work gives even further credence to these words of Victor Hugo: Les mathématiques ne sont pas une moindre immensité que la mer. From all of us: Merci beaucoup, et tout le meilleur!

Acknowledgements I am grateful to László Márki, Jean-Eric Pin, Austin Scirratt, Charles Wells and especially to the subject of this article for the their input and timely help during stages of its preparation. 